\title{
Os estudos do lazer e a apropriação da obra de Marx e Engels - Maria Isabel Leme Faleiros - ${ }^{1}$
}

\begin{abstract}
Resumo: Estudo do estado da arte dos estudos do lazer no Brasil, concentrado nos trabalhos que apropriam a obra de Marx, produzidos e disseminados em periódicos e editoras nacionais (década de 80). Transitando entre a colocação do lazer como prática social estritamente limitada à esfera da produção e da reprodução da existência; o vislumbre de possibilidades/perspectivas emancipatórias nesta prática social; e a total negação do trabalho/lazer como esferas de realização humana, estes textos apresentam aos leitores a instigante questão das perspectivas do trabalho e do lazer da necessidade e da liberdade - na sociedade capitalista e no projeto comunista.
\end{abstract}

Palavras-chave: Atividades de lazer. Brasil. Literatura. Comunismo. Karl Marx. Friedrich Engels.

\section{INTRODUÇÃO}

Há no Brasil um conjunto de estudos multidisciplinares preocupados com a ocupação do tempo livre, reconhecidos genericamente como estudos do lazer. A regularidade destes estudos pode ser observada a partir da década de 30 do século XX, caracterizando-se, primeiramente, (1) pelas discussões em torno da regulamentação da duração da jornada de trabalho e da capacidade do trabalhador para vivenciar o lazer decorrente da redução da jornada (SODRÉ, 1938); (2) pela produção de uma política pública de ocupação do tempo livre de crianças, menores trabalhadores ou não (MARCASSA, 2002; GOMES, 2003).

Ao mesmo tempo, principalmente na década de 40, no campo do direito, inicia-se uma série de discussões acerca da necessidade

\footnotetext{
${ }^{1}$ Uma versão deste trabalho foi apresentada durante o II Encontro Brasileiro de Educação e Marxismo, em 06-08 de agosto/2006, UFPR. Aqui, apresentamos o trabalho reformulado incorporando citações e referências que confirmam a tese que nele defendemos.

* Elza Margarida de Mendonça Peixoto. Mestre. Doutoranda no PPG em Educação - UNICAMP. Professora do Dep. de Estudos do Movimento Humano da Universidade Estadual de Londrina. E-mail: epeixoto@uel.br.
} 
funcional do tempo livre em virtude dos benefícios para a recuperação do trabalhador, contrabalançadas com a tentativa de garantir a direção da ocupação deste tempo liberado com um programa de atividades dirigidas pelo Estado e implementadas recorrendo-se à estrutura sindical, em uma clara intenção de concessão tutelada de tempo livre aos trabalhadores (SUSSEKIND, 1946, 1948, 1950, 1952).

O conjunto destas ações contextualiza-se no projeto de conformação da classe operária em todo o mundo e no Brasil (PICHELI, 1997; BRAGA, 2005; GANDRA, SILVA e NASCIMENTO, 2005), configurando-se como componente essencial do projeto de contenção da organização dos trabalhadores, sob o impacto do temor dos avanços do comunismo no mundo, de que são frutos a CLT e o Sistema "S".

Expondo o estágio do desenvolvimento dos conflitos de classe durante a Primeira República, Fausto comentará:

Desde o início da Primeira República, surgiram expressões da organização e mobilização dos trabalhadores: partidos operários, aliás, com poucos operários, que logo desapareceram, sindicatos, greves. Os anarquistas tentaram mesmo organizar a classe operária no nível nacional, com a criação da Confederação Operária Brasileira em 1906. Mas o movimento era esparso e raramente despertava a atenção e preocupação da elite. Obtinham-se direitos pressionando os patrões, sem que eles fossem assegurados em lei. Passado o momento da pressão, os direitos se perdiam.

Esse quadro foi interrompido entre 1917 e 1920, quando um ciclo de greves de grandes proporções surgiu nas principais cidades do país, especialmente no Rio de Janeiro e em São Paulo. Na raiz desse ciclo estavam dois fatores: primeiro, o agravamento da carestia, em consequiência das perturbações causadas pela Primeira Guerra Mundial e pela especulação com gêneros alimentícios; segundo, a existência de uma vaga revolucionária na Europa, aberta com a Revolução de Fevereiro, seguida da Revolução de Outubro de 1917, na Rússia czarista. O movimento operário passou a ser objeto de

Movimento, Porto Alegre, v.13, n. 02, p.197-218, maio/agosto de 2007. 
preocupações e ganhou a primeira página dos jornais (FAUSTO, 2006, p.169).

No âmbito do direito trabalhista, observa-se o esforço de alinhamento internacional com relação à preocupação com a regulamentação da jornada de trabalho, regulamentação do repouso remunerado e com relação a uma política de tutela do tempo livre. $\mathrm{O}$ intercâmbio com algumas experiências americana, francesa e alemã é uma constante durante estas primeiras décadas. ${ }^{2}$

Neste movimento de preocupação com a ocupação do tempo livre, inicia-se o conjunto da produção do conhecimento correspondente aos estudos do lazer no século XX, gerando, nas décadas de 30, 40 e 50, os Manuais de Recreação centrados na educação voltada para a apreensão de normas e padrões de convívio social e para a ocupação do tempo livre, e na oferta de acervo de jogos, brinquedos, brincadeiras e outras atividades consideradas adequadas do ponto de vista da formação moral e da manutenção da saúde. No âmbito das políticas públicas, entre as décadas de 20 e 40, são implementados, por iniciativa do Estado e do empresariado, os Jardins de Recreio em Porto Alegre, os Clubes de Menores Operários e Parques Infantis em São Paulo, o Serviço de Recreação Operária no Distrito Federal e o Sistema $S$ em caráter nacional, atendendo aos trabalhadores da Indústria (SESI) e do Comércio $(\mathrm{SESC}){ }^{3}$

Nas décadas de 60 e 70, configura-se a preocupação com a formação de pessoal qualificado para o gerenciamento, a produção do conhecimento e a prestação de serviços em lazer somada à necessidade de primeiros relatos das experiências já desenvolvidas, à discussão de uma política nacional de recreação e lazer, ao aprimoramento das discussões e referências do ponto de vista teórico e ao diagnóstico de atividades privilegiadas pelos trabalhadores na

\footnotetext{
2 Gomes (2003) refere-se às viagens de Frederico Guilherme Gaelzer, responsável pela implementação dos Jardins de Recreio em Porto Alegre, para os Estados Unidos e para a Alemanha. O levantamento das obras de Nicanor Miranda demonstra que o autor participou de encontros internacionais relatando a experiência de Recreação Pública em São Paulo (consultar Sistema de Bibliotecas da USP). Ethel Bauzer Medeiros participa ativamente de diversos eventos e organizações internacionais (MEDEIROS, 2003). Arnaldo Sussekind compõe todas as delegações enviadas às Convenções da OIT (SUSSEKIND, 2004). ${ }^{3}$ Ver Picheli (1997), Gomes (2003), Marcassa (2002) e Braga (2005).

Movimento, Porto Alegre, v.13, n. 02, p.197-218, maio/agosto de 2007.
} 
ocupação de seu tempo livre do trabalho (SANT'ANNA, 1994). Neste período, são realizados os primeiros cursos de pós-graduação, ${ }^{4}$ os primeiros encontros nacionais, ${ }^{5}$ as primeiras revistas especializadas $^{6}$ e os primeiros grupos de estudos. ${ }^{7}$

Um levantamento bibliográfico permitiu localizar uma produção de 2.664 trabalhos referentes aos estudos do lazer no Brasil. Dentre estes, 102 trabalhos de 63 autores fazem referências à obra de Marx e Engels (1) no título dos trabalhos; (2) nas referências bibliográficas; (3) no corpo de artigos publicados em periódicos, livros, capítulos de livros e trabalhos publicados em anais de eventos. A partir deste levantamento, observa-se a referência à obra de Marx na década de 30 (SODRÉ, 1938), na década de 50 (SUSSEKIND, 1950), e, até este momento, a ausência de referências nas décadas de 60 e 70, com retomada a partir da década de 80 em diante.

Até a década de 80, as referências estão marcadas pela necessidade de reconhecer o papel da obra de Marx na organização das lutas dos trabalhadores, ao tempo em que se explicita o temor despertado por esta organização e a necessidade de sua contenção por meio do atendimento antecipado e preventivo das reivindicações dos trabalhadores. Por razões óbvias, ocorre um apagamento desta referência - nos trabalhos até aqui analisados - nas décadas de 60 e 70 (Ditadura Militar). Na década de 80, a apropriação da obra de Marx e Engels assume uma conotação política, recorrendo-se a ele

\footnotetext{
${ }^{4}$ Localizamos, no Currículo Lattes de Lamartine Pereira da Costa, a referência ao Curso de Especialização em Recreação Operária, oferecido pelo Serviço de Recreação Operária da Comissão do Imposto Sindical, SROCIS, Brasil. Nos anos de 1975 e 1976, a Pontifícia Universidade Católica do Rio Grande do Sul (PUC-RS) ofereceu o que parece ter sido o Primeiro Curso de Especialização em Lazer e Recreação, com Carga Horária de 465h. Kátia Brandão Cavalcanti participa deste curso, produzindo a monografia O Semilazer no Trabalho do Animador. Ano de finalização: 1976. Orientador: Suzana Kilpp. Fonte: Currículos da Plataforma Lattes.

${ }^{5}$ Em 1969, a Secretaria do Bem-estar do Município de São Paulo, em conjunto com o SESCSP, promoveram um congresso intitulado Seminário sobre Lazer cujo subtítulo era "Perspectiva para uma cidade que trabalha”. Em 1974, o CELAR (PUC-RS) realiza o I Encontro Estadual sobre Lazer e Recreação. Em 1975, o SESC-RJ realiza o I Encontro Nacional sobre Lazer (Cultura, Recreação e Educação Física). Em 1976, o SESC-RJ realiza o I Encontro Nacional de Recreação em que são relatadas as experiências de seus Departamentos Regionais. ${ }^{6}$ Referimo-nos aos Cadernos de Lazer, publicado a partir de 1977 (São Paulo: SESC: Brasilense, 1977) e ao Boletim de Intercâmbio (1980).

7 Em convênio entre a Prefeitura Municipal de Porto Alegre e a PUC/RS, surge o CELAR (1973-1978). O SESC-SP implementou o CELAZER (1978-1984).
}

Movimento, Porto Alegre, v.13, n. 02, p.197-218, maio/agosto de 2007. 
para o enfrentamento das visões funcionalistas - no âmbito específico dos estudos e das políticas públicas em lazer - representadas principalmente, pela Sociologia Empírica do Lazer de Jofre Dumazedier, disseminada no Brasil pela Editora Perspectiva ${ }^{8}$ e pelo Serviço Social do Comércio.

Dentre os autores que participam deste movimento, citamos Faleiros (1980), Reale (1980), Oliveira (1986), Lopes (1986), Cunha (1987) e Marcellino $(1983,1987)$. Nesta década, a referência mais freqüente a Marx, caracteriza-se por duas posições básicas: (1) afirmação de que Marx é o responsável teórico por um elogio ao trabalho que se dissemina subsidiando a ênfase à produtividade, fundamento de uma visão que ora nega o lazer, ora o subordina ao trabalho, enquanto tempo de recuperação, considerado como um ponto comum entre socialistas e comunistas (REALE, 1980; MARCELLINO, 1983, 1987); (2) questionamento teórico da Sociologia Empírica do Lazer de Dumazedier e das teses que defendem que a sociedade caminha para uma sociedade do lazer, correntes no âmbito dos estudos do lazer veiculados no Brasil na década de 70 (FALEIROS, 1980; OLIVEIRA, 1986; LOPES, 1986; CUNHA, 1987).

Deste segundo grupo de textos, desejamos colocar em discussão neste trabalho, especificamente, a obra de Faleiros, em virtude do esforço evidente de apropriação disciplinada e rigorosa das categorias centrais na obra de Marx para a explicação do lazer. Reconhecemos a necessidade de uma análise detida dos fundamentos dos debates realizados nesta década, destacando a necessidade de incorporar na análise as entrevistas com os pesquisadores envolvidos neste debate, que possibilitem reconhecer as fontes em que estavam bebendo para posicionar-se assim como o que desejavam com suas reflexões, uma vez que, embora vivenciássemos a abertura política, o temor

\footnotetext{
${ }^{8}$ Nas décadas de 60, 70 e 80, a Editora Perspectiva, o Serviço Social do Comércio, a Editora Kairós, a Livraria Pioneira Editora, a Companhia Editora Nacional e Zahar publicaram uma série de títulos de autores estrangeiros (Lafargue, Mills, Marcuse, Riesmann, Parker, Veblen, Russel) que apresentavam elementos para a discussão da problemática do lazer, predominando aí as abordagens sociológicas. Embora não tenhamos analisado estes títulos, estudos preliminares apontam que neles expressava-se o embate das visões funcionalista e marxiana quanto a esta problemática.
}

Movimento, Porto Alegre, v.13, n. 02, p.197-218, maio/agosto de 2007. 
de pronunciamentos públicos estava arraigado entre os intelectuais brasileiros fortemente atingidos pela repressão que devastou o pensamento crítico e de esquerda no Brasil.

Não podemos deixar de destacar - algo óbvio para os que estudam a obra de Marx e Engels - a evidência de desconhecimento do pensamento destes autores por parte daqueles que afirmam encontrar neles um elogio do trabalho ou da produtividade. ${ }^{9}$ Estes autores confundem a constatação de Marx de que o trabalho é a ação primeira na relação homem/natureza com o elogio ao trabalho independente das formas que assuma em diferentes períodos históricos. A crítica de Marx à forma trabalho no modo capitalista de produção da existência, e toda a desumanização que ocasiona, presente nos Manuscritos econômicos e filosóficos de 1848, nos Grundrisse e em todo $O$ capital são suficientes para derrubar esta afirmação superficial, porque desconhecedora do conjunto da obra de Marx.

\section{MARIA ISABEL LEME FALEIROS - REPENSANDO O LAZER}

No âmbito da apropriação da obra de Marx com a finalidade de interpretação da problemática do lazer, destacamos a iniciativa de Maria Isabel Leme Faleiros, que, em artigo publicado na Revista Perspectiva, em 1980, propõe-se repensar o lazer, em um debate aberto com as posições de Jofre Dumazedier. Como vai aparecer a apropriação da obra de Marx e Engels no trabalho desta autora?

Em Repensando o lazer, Faleiros coloca em cheque a estrutura explicativa proposta por Dumazedier para a problemática do lazer em seu clássico Sociologia Empírica do Lazer, que circulava no Brasil desde 1974. Destacando que grande parte dos estudos sobre o lazer que, naquele momento, realizavam uma definição do objeto, o fazia recorrendo à definição elaborada pelo autor, Faleiros vai acentuar que sua obra "[...] associa as atividades de lazer à satisfação de determinadas necessidades humanas" (descanso, divertimento, recreação, entretenimento e desenvolvimento da personalidade). Mas Dumazedier " [...] não consegue apanhar a dinâmica

${ }^{9} \mathrm{Em}$ outro artigo, em fase de preparação para publicação, aprofundamos este debate.

Movimento, Porto Alegre, v.13, n. 02, p.197-218, maio/agosto de 2007. 
social que permite essas manifestações [...]", na medida em que "seus trabalhos mostram [...] apenas a existência de conjuntos de atividades diferenciadas, as relações existentes entres essas e outras que não são classificadas como lazer e as perspectivas quanto às tendências de manifestação dessas atividades". Tal ocorre porque a explicação que Dumazedier constrói para as "[...] necessidades da sociedade, de suas classes e grupos" que levam à configuração do lazer como problemática social, "[...] se faz através da estrutura lógica do funcionalismo". Destacando Mallinovski como "[...] um dos elementos mais representativos dessa corrente", Faleiros (1980) analisa, recorrendo a trechos da obra do autor, as premissas de sua teoria das necessidades destacando que este autor/corrente “[...] não introduz o caráter histórico das necessidades e privilegia o nível institucional, a mudança ficando atrelada apenas a este nível”, concluindo que a análise de Dumazedier, “[...] utilizando o mesmo raciocínio" fica limitada "[...] às funções que as atividades de lazer preenchem ou podem vir a preencher" (FALEIROS, 1980, p.51-53).

Ao mesmo tempo, a autora analisa a explicação de Baudrillard para a problemática do lazer e a estrutura "[...] que Baudrillard utiliza para explicar um dos aspectos do modo de produção capitalista, o consumo dos objetos", introduzindo "a idéia de diferenciação". Explica que o autor "[...] refuta a mística da igualdade vinculada à ideologia da 'sociedade do Bem-Estar' e propõe uma fórmula teórica que recorre a estruturas formais para explicar a equação necessidade/satisfação na "sociedade de consumo", destacando que para o sociólogo e filósofo francês a explicação para o consumo está na necessidade da diferença. Faleiros (1980) analisa a estrutura explicativa do pensamento do autor concluindo que "[...] na medida em que esta análise parte da categoria consumo, que já é resultado, ela não retém condições para uma explicação suficiente dos grupos sociais e, muito menos, para a análise das classes sociais". A autora destaca que neste autor, "[...] a contradição peculiar ao sistema capitalista foi resolvida pela diferenciação". Assim, também Baudrillard, apoiado em estruturas explicativas típicas da lógica formal, "[...] fica limitado ao nível formal e aparente da

Movimento, Porto Alegre, v.13, n. 02, p.197-218, maio/agosto de 2007. 
relação produção-consumo", sendo também limitado para compreender a problemática do lazer (FALEIROS, 1980, p. 53-55).

É em Marx que Faleiros (1980) reconhece a possibilidade de construção de teoria explicativa que contemple a dinâmica social em que esta problemática está inscrita. Para realizar este movimento, trabalha a noção de produção da existência presente nas obras centrais do autor: A ideologia alemã (1845-1846), Manuscritos econômicos e filosóficos (1844); A Miséria da Filosofia (1847); Contribuição à crítica da economia política (1859) e $O$ capital (1867). ${ }^{10}$ Faleiros elege a noção de modo de produção da existência, cunhada por Marx e Engels, como o princípio teórico que permite compreender o que aparece em seu texto como os diversos "[...] setores do modo de vida" do homem:

\begin{abstract}
Se buscamos entender determinadas manifestações sociais que ocorrem no modo de vida de um determinado grupo, temos que recorrer à análise dos mecanismos responsáveis pelo processo social mais amplo vivenciado por esse grupo. Partimos do pressuposto de que são as suas condições de existência que moldam todos os setores do seu modo de vida (FALEIROS, 1980, p. 56).
\end{abstract}

Em primeiro lugar, destaca que Marx " [...] buscando explicar o funcionamento do modo de produção capitalista, também parte (tal como Mallinovski), de forma particular" do "princípio da satisfação das necessidades". A autora comprova esta tese, recordando o pressuposto de que Marx parte de que para viver os homens necessitam comer, beber, habitar, vestir-se, portanto, que "[...] a primeira realidade histórica é a produção dos meios que permitam satisfazer tais necessidades". Mas a produção assume uma característica interpretativa na exposição de Faleiros:

As limitações apontadas nas propostas de Malinowski e Baudrillard nos levam a continuar a incursão no pensamento de Marx para resolver algumas questões que ainda permanecem. A primeira

10 Citamos aqui as datas originais de produção destes trabalhos por Marx. Edições destas obras publicadas no Brasil são informadas nas referências deste artigo.

Movimento, Porto Alegre, v.13, n. 02, p.197-218, maio/agosto de 2007. 
delas diz respeito à categoria que ele introduz na equação necessidades/satisfação: através do seu caráter de utilidade, o trabalho humano é sempre o veículo de intercâmbio entre o homem e a natureza na busca da sua sobrevivência. [...] na produção, os membros da sociedade se apropriam dos produtos da natureza para as necessidades humanas; [...]. A produção facilita os objetos que respondem às necessidades; [...] Nesse sentido, os homens são compelidos a realizar diversas modalidades de produção voltadas para o atendimento das diferentes necessidades, desde aquelas ligadas à reprodução biológica do grupo, como também as necessidades intelectuais, estéticas, etc.

Ao produzirem, os indivíduos não só consomem os meios de trabalho, enquanto objeto e instrumento, mas também as suas próprias energias, que, por sua vez, requerem uma nova produção para serem repostas. "A produção é, pois, imediatamente consumo, este é imediatamente produção. Cada qual é imediatamente seu contrário.” O consumo também dá lugar à produção porque “... cria a necessidades de uma nova produção [...]. Ao mesmo tempo que uma determinada necessidade requer a produção para a sua satisfação, o ato de consumo que visa a satisfação torna a criar a necessidade de produção. "Produção consumidora. Consumo produtivo". A necessidade passa a ser, assim, a mediadora do processo de produção da subsistência de todo grupo social (FALEIROS, 1980, p. 56).

Se Faleiros avança ao constatar a produção e a reprodução da vida como a esfera central para a compreensão da problemática do lazer, por outro lado, apresenta problemas na interpretação da noção de trabalho e produção presentes na obra de Marx. Em primeiro lugar, Marx não introduz uma categoria "na equação necessidade/ satisfação". Marx constata na realidade objetiva que a satisfação das necessidades humanas depende da própria atividade humana: o trabalho; da atividade própria do homem enquanto ser genérico. Assim, em Marx, o trabalho não é um veículo, uma mediação, mas a forma genérica, uma determinação, a atividade mesma de apropriação

Movimento, Porto Alegre, v.13, n. 02, p.197-218, maio/agosto de 2007. 
do mundo e de imposição de sua marca. Esta questão aparece claramente configurada em Trabalho alienado e superação positiva da auto-alienação humana (MARX, 1989, p. 154-157):

O homem é um ser genérico, não só na medida em que teórica e praticamente faz do gênero tanto do seu próprio quanto do das demais coisas, o seu objeto, mas também - e isto é apenas uma outra expressão para a mesma coisa - na medida em que se relaciona consigo mesmo como com o gênero vivo, presente, na medida em que se relaciona consigo mesmo como com um ser universal e por isso livre.

Tanto no homem quanto no animal a vida do gênero consiste fisicamente em que o homem (tal como o animal) vive da natureza inorgânica, e quanto mais universal o homem é do que o animal, tanto mais universal é o âmbito da natureza inorgânica da qual vive. Assim como plantas, animais, pedras, ar, luz, etc., formam teoricamente uma parte da consciência humana, em parte como objetos da Ciência Natural e em parte como objetos da arte - a sua natureza inorgânica espiritual, meios de vida espirituais que ele tem primeiro que preparar para a fruição e a digestão -, assim também formam praticamente uma parte da vida humana e da atividade humana. Fisicamente o homem vive só destes produtos da natureza, quer apareçam na forma de alimento, calefação, vestuário, moradia, etc. Na prática, a universalidade do homem aparece, precisamente na universalidade que faz da natureza inteira o seu corpo inorgânico, tanto na medida em que ela é 1 . um meio de vida imediato, quanto na medida em que é 2. a matéria, o objeto e o instrumento da sua atividade vital. A natureza é o corpo inorgânico do homem, a saber, a natureza na medida em que ela mesma não é o corpo humano. O homem vive da natureza, significa: a natureza é o seu corpo, com o qual tem que permanecer em constante processo para não morrer. Que a vida física e mental do homem está interligada com a natureza não tem outro sentido senão que a natureza está interligada consigo mesma, pois o homem é uma parte da natureza.

Na medida em que o trabalho alienado aliena do homem 1. a natureza e 2. a si mesmo, a sua função

Movimento, Porto Alegre, v.13, n. 02, p.197-218, maio/agosto de 2007. 
ativa própria, a sua atividade vital, aliena do homem o gênero; the faz da vida do gênero um meio de vida individual. Em primeiro lugar, aliena a vida do gênero e a vida individual, e em segundo lugar, faz da última, em sua abstração um fim da primeira, igualmente na sua forma abstrata e alienada. [...]

$\mathrm{O}$ animal é imediatamente um com a sua atividade vital. Não se distingue dela. É ela. O homem faz da sua atividade vital mesma um objeto do seu querer e da sua consciência. Tem atividade vital consciente. Não é uma determinidade com a qual ele conflua imeditamente. A atividade vital consciente distingue o homem imediatamente da atividade vital animal. É precisamente só por isso que ele é um ser genérico. Ou ele só é um ser consciente, isto é, a sua própria vida lhe é objeto, precisamente porque é um ser genérico. Só por isto a sua atividade é atividade livre. O trabalho alienado inverte a relação de maneira tal que precisamente porque é um ser consciente o homem faz da sua atividade vital, da sua essência, apenas um meio para a sua existência.

[...] Claro que o animal também produz. Constrói um ninho, moradas para si, tal como a abelha, castor, formiga, etc. Só que produz apenas o que precisa imediatamente para si ou seu filhote; produz unilateralmente, ao passo que o homem produz universalmente; produz apenas sob o domínio da necessidade física imediata, ao passo que o homem produz mesmo livre da necessidade física e só produz verdadeiramente sendo livre da mesma; só produz a si mesmo, ao passo que o homem reproduz a natureza inteira; o seu produto pertence imediatamente ao seu corpo físico, ao passo que o homem se defronta livre com o seu produto. $\mathrm{O}$ animal forma só segundo a medida e a necessidade da species à qual pertence, ao passo que o homem sabe produzir segundo a medida de qualquer species e sabe em toda parte aplicar a medida inerente ao objeto; por isso o homem também forma segundo as leis da beleza.

Portanto, é precisamente ao trabalhar o mundo objetivo que o homem primeiro se prova de maneira efetiva como um ser genérico. Esta produção é a

Movimento, Porto Alegre, v.13, n. 02, p.197-218, maio/agosto de 2007. 
sua vida genérica operativa. Por ela, a natureza aparece como a sua obra e a sua realidade efetiva. O objeto do trabalho é, portanto, a objetivação da vida genérica do homem: ao se duplicar não só intelectualmente tal como na consciência, mas operativa, efetivamente e portanto ao se intuir a si mesmo num mundo criado por ele. Por conseguinte, ao arrancar do homem o objeto de sua produção, o trabalho alienado lhe arranca a sua vida genérica, a sua objetividade genérica efetivamente real e transforma a sua vantagem ante o animal na desvantagem de lhe ser tirado o seu corpo inorgânico, a natureza (MARX, 1989, p 154157). ${ }^{11}$

Nos Grundrisse (1857-1858):

O divórcio da propriedade e do trabalho constitui uma lei necessária da troca entre capital e trabalho. Como não-capital, o trabalho enquanto tal se postula: 1) Não como trabalho objetivado, concebido negativamente (por si mesmo todavia objetivo; o não objetivado mesmo em forma objetiva). Como tal, não é tampouco matéria-prima, nem instrumento de trabalho, nem produto em bruto: é trabalho separado de todos os meios e objetos de trabalho, de todo objeto exterior. O trabalho vivo se abstrai, pois, dos elementos de sua própria realidade (é, por conseguinte, um não valor); esta total privação de objetividade reduz o trabalho à pura subjetividade. O trabalho é a pobreza absoluta, não só porque carece de riqueza material, senão porque, além disso, se acha plenamente excluído dela. Dito de outro modo, o trabalho não possui valor; é, portanto, um valor de uso puramente objetivo, que, por carecer de mediador, não pode ser outra coisa que esta objetividade vinculada à pessoa e que coincide diretamente com a pessoa [física] do trabalhador. E, ao ser puramente imediata, esta objetividade é também uma não-objetividade imediata. Dito em outros termos, o indivíduo carece de objetividade,

${ }^{11}$ Outras versões deste texto estão publicadas sob a organização de Ranieri na Revista Idéias (MARX, 2003) e pela Editora Boitempo (MARX, 2004); e de Giannotti, na Editora Abril (MARX, 1978).

Movimento, Porto Alegre, v.13, n. 02, p.197-218, maio/agosto de 2007. 
fora de sua própria existência imediata. 2) Não como trabalho objetivado, nem que possui valor, concebido positivamente. O trabalho, é certo, apresenta primeiramente uma relação de negatividade com respeito a si mesmo, é o trabalho [ainda] não objetivado, quer dizer, carente de objeto e que possui, portanto, uma existência meramente subjetiva. Mas, ainda que o trabalho careça de objeto, é uma atividade; pode não ter um valor por si mesmo, mas é a fonte viva do valor. A riqueza geral aparece objetivada como realidade no capital, mas como possibilidade geral se dá no trabalho e se comprova na ação. Nada tem de contraditório - ou, melhor dito, esta contradição nos termos já vistos se desprende da natureza mesma da coisa - que o trabalho, de uma parte, tenha por objeto a pobreza absoluta e, de outra parte, represente, como sujeito e como atividade, a possibilidade geral da riqueza; ambas as coisas derivam da essência mesma do trabalho, enquanto premissa do capital, como antítese dele, como existência antitética do capital mesmo, que, por sua vez, pressupõe o capital como existência antitética sua. (MARX, 1985, p. 178)

\section{Ou em O capital (1867), a belíssima definição:}

Antes de tudo, o trabalho é um processo de que participam o homem e a natureza, processo em que o ser humano com sua própria ação, impulsiona, regula e controla seu intercâmbio material com a natureza. Defronta-se com a natureza como uma de suas forças. Põe em movimento as forças naturais de seu corpo, braços e pernas, cabeça e mãos, a fim de apropriar-se dos recursos da natureza, imprimindo-lhes forma útil à vida humana. Atuando assim sobre a natureza externa e modificando-a, ao mesmo tempo, modifica sua própria natureza. Desenvolve as potencialidades nela adormecidas e submete ao seu domínio o jogo das forças naturais. Não se trata aqui das formas instintivas, animais, do trabalho. Quando o trabalhador chega ao mercado para vender, é imensa a distância histórica que medeia entre sua condição e a do homem primitivo com a sua forma ainda instintiva de trabalho. Pressupomos o trabalho

Movimento, Porto Alegre, v.13, n. 02, p.197-218, maio/agosto de 2007. 


\begin{abstract}
sob a forma exclusivamente humana. Uma aranha executa operações semelhantes à do tecelão, e a abelha supera mais de um arquiteto ao construir sua colméia. Mas o que distingue o pior arquiteto da melhor abelha é que ele figura na mente sua construção antes de torná-la realidade. No fim do processo de trabalho aparece um resultado que já existia antes idealmente na imaginação do trabalhador. Ele não transforma apenas o material sobre o qual opera; ele imprime ao material o projeto que tinha conscientemente em mira, o qual constitui a lei determinante do seu modo de operar e ao qual tem de subordinar sua vontade. E essa subordinação não é um ato fortuito. Além do esforço dos órgãos que trabalham, é mister a vontade adequada que se manifesta através da atenção durante todo o curso do trabalho. E isto é tanto mais necessário quanto menos se sinta o trabalhador atraído pelo conteúdo e pelo método de execução de sua tarefa, que lhe oferece por isso menos possibilidade de fruir da aplicação das suas próprias forças físicas e espirituais. (MARX, 1989, p. 202)
\end{abstract}

Destacando que Marx não hierarquiza as necessidades e que as vincula historicamente, a autora assinala uma geração contínua de novas necessidades à medida de sua satisfação, que permite localizar necessidades de ordem natural e necessidades de ordem sociais e históricas, necessidades biológicas objetivas e necessidades subjetivas (intelectuais e estéticas). Ao recuperar o processo histórico que origina a lógica da produção, Faleiros traz para o centro da explicação da equação necessidade/satisfação a existência objetiva dos homens. Mas, ao mesmo tempo, parece desmaterializar as necessidades que chama de subjetivas. Entende que a "necessidade" em Marx "[...] é a mediadora do processo de produção da substância de todo o grupo social". A meu ver, em Marx, a necessidade não aparece como mediadora, mas como impulsionadora de toda a atividade humana, uma vez que não atendendo às necessidades nele entranhadas, arrisca-se à extinção. $\mathrm{O}$ homem avança, historicamente, porque necessita sobreviver individual e coletivamente. Esta é uma necessidade material individual e coletiva e não uma necessidade subjetiva abstrata. A necessidade que fundamenta o pensamento de Marx é em si material, porque é a própria entranha humana; única e perene

Movimento, Porto Alegre, v.13, n. 02, p.197-218, maio/agosto de 2007. 
forma de sua existência. A sobrevivência da coletividade, ainda que inconsciente, é pré-requisito da atividade dos indivíduos na produção de sua existência imediata e histórica.

Como a noção de trabalho de Marx é apropriada por Faleiros? Neste processo, Faleiros atribui centralidade às noções de trabalho e modo de produção da existência, mas estas, em seu pensamento, aparecem dissociadas. Faleiros entende o trabalho como um veículo. A separação que se opera entre trabalho e modo de produção da existência indica uma compreensão fragmentada, e de certa forma idealista, da noção que Marx e Engels elaboram em $A$ ideologia alemã. A autora diz: “[...] através do seu caráter de utilidade, o trabalho humano é sempre o veículo de intercâmbio entre o homem e a natureza na busca da sua sobrevivência". As noções de trabalho e modo de produção da existência aparecem dissociadas em Faleiros, porque o trabalho não aparece nesta autora como atividade vital (tal como em Marx), mas como artefato (como ferramenta) que media a relação entre homem (uma entidade?) e o mundo natural e real.

Porque em Faleiros trabalho e produção aparecem como ações diferenciadas? Parece-me revelar-se aqui uma noção de homem não-materialista: há um homem dentro do homem que se relaciona com o mundo real recorrendo a uma ferramenta. O homem real torna-se apagado a fim de que o homem-idéia possa comunicar-se com o mundo real. Se Faleiros (1980) capta o modo de produção da existência como categoria central na obra de Marx, se apresenta uma teoria completa sobre a satisfação das necessidades como eixo do aparecimento do lazer como prática social; interpreta o trabalho como um veículo, e a necessidade como mediação, revelando, assim, a noção de homem que a orienta. A meu ver, este é o limite da exposição de Faleiros; mas um limite teórico (quase imperceptível) estrutural de tal monta, traz quais conseqüências para o esforço da autora de construir uma explicação teórica para o lazer baseada na concepção materialista da história. Quais as implicações que a apropriação que Faleiros faz da obra de Marx trás para os estudos do lazer?

Considerando as necessidades, "na busca do entendimento do lazer", como sendo "[...] determinadas forças que levam os homens

Movimento, Porto Alegre, v.13, n. 02, p.197-218, maio/agosto de 2007. 
a buscarem a sua satisfação no mundo exterior, tanto físico quanto social", a autora afirma que "[...] sua evolução e multiplicação não se dão ao nível das necessidades, propriamente, mas nas formas de satisfazê-las". Na medida em que se desenvolvem as forças produtivas, processo no qual o homem é cada vez mais liberado de um "estado de natureza", os meios de resposta às necessidades vão sendo refinados e diversificados. Buscando "[...] um caminho que não seja nem organizado apenas pelo mundo da aparência, nem por um código lógico de diferenciação social" - respectivamente detectados em Dumazedier e em Baudrillard - a autora recorre a Marx.

Conclui: (1) o tempo liberado retém o consumo e a produção; (2) o valor da mercadoria força de trabalho é determinado pelo tempo de trabalho necessário à sua própria produção, o que permite dizer que o tempo chamado livre é tempo incluso no custo da força de trabalho, portanto, pago pelo próprio trabalhador no processo de produção; (3) os princípios que norteiam a produção capitalista se estendem a todas as esferas de produção - para produzir mercadorias uso máximo da força de trabalho, para manter a produção de mercadorias, um tempo para o repouso e o consumo; (4) o tempo livre não é livre; todo o tempo liberado da jornada de trabalho é mercadoria.

Consumindo o resultado da produção, o indivíduo recupera a energia consumida no trabalho, produzindo novas energias e a necessidade, uma nova produção. Pelas articulações todas que, nesse nível, desenvolvem-se entre os homens, criam-se necessidades de novos produtos, diferentes serviços, etc. Somente nesse contexto podemos construir uma explicação suficiente para a problemática atual do lazer, enquanto determinadas atividades que se desenvolvem num tempo que, além de ser em si mesmo uma mercadoria, é veículo para circulação de outras mercadorias. E com esta natureza, o tempo tem duplo aspecto: valor de uso, na medida em que tem determinadas utilidades voltadas para a satisfação das necessidades, sendo que a mais geral é a própria recomposição da força de trabalho, e valor de troca, "porque nesse está corporificado,

Movimento, Porto Alegre, v.13, n. 02, p.197-218, maio/agosto de 2007. 
materializado, trabalho humano abstrato" (FALEIROS, 1980, p.63).

Com base nestes parâmetros, Faleiros vai dizer que (1) todas as sociedades humanas produziram formas de lazer; (2) a aparência de novidade dá-se porque o capitalismo expande-se "[...] a todos os campos da atividade humana fora da esfera da produção"; (3) as necessidades humanas perdem o caráter natural para adquirir o caráter histórico e social - mas só no capitalismo as necessidades passam a ser satisfeitas através de mercadorias; (4) no capitalismo, as atividades caracterizadas como lazer, passaram a reproduzir esse processo mais amplo; (5) o lazer deve ser reconhecido em sua relação com o trabalho, como atividades que ocorrem no tempo de não-trabalho, voltadas para a satisfação da necessidade de reconstituição e reprodução da força de trabalho.

Faleiros traz importantíssimas contribuições para que compreendamos a inscrição do lazer na lógica de mercado, na medida em que (1) recupera a lógica da satisfação da necessidade que leva à produção; (2) pontua as características que a satisfação das necessidades assume no modo capitalista de produção; (3) aponta o referencial marxista como referencial central para a interpretação deste processo. No entanto, sua reflexão apresenta-se limitada, na medida em que sua análise reduz o lazer à reposição da força de trabalho, apagando as contradições dialéticas que também no lazer se configuram. Aqui, trata-se de superar a idéia de providência como algo externo ao homem, pela materialidade da providência como ação do próprio homem a fim de sobreviver. A exposição de Faleiros apaga a perspectiva da luta de classes e a revolução, na medida em que apresenta o trabalhador como exclusivamente dominado pela lógica do capital. Em seu raciocínio, são apagadas as contradições dialéticas que a prática social do lazer, na totalidade da lógica da existência no modo de produção capitalista, também engendra. A nosso ver, a raiz destas características de seu texto está na compreensão limitada de trabalho que apresenta.

\section{CONSIDERAÇÕES PROVISÓRIAS}

Na década de 80, na chamada lenta e gradual transição da ditadura para a democracia, na contramão da negação da centralidade

Movimento, Porto Alegre, v.13, n. 02, p.197-218, maio/agosto de 2007. 
do trabalho entre os estudos do lazer, às vésperas do fim da experiência socialista na URSS, Faleiros recupera a obra de Marx, com a finalidade de construção de uma teoria explicativa para esta problemática, fornecendo um referencial atualíssimo no que toca ao entendimento do lazer como categoria interna ao modo capitalista de produção da existência, uma prática social destinada à satisfação das necessidades e a circulação de mercadorias.

No entanto, no processo de busca de uma teoria explicativa para o lazer enquanto prática social, Faleiros apaga a perspectiva da revolução posta no próprio processo de configuração da luta de classes como motor da história. Sua busca pela compreensão do lazer no contexto da teoria de Marx aparece desprovida do eixo central na obra do autor: o modo de produção e reprodução da existência de tipo capitalista engendra relações contraditórias e dialéticas que levam à sua destruição. Obviamente, este apagamento pode ser explicado pelo contexto político e econômico caracterizado pelo autoritarismo: revolução é palavra autorizada apenas para referir-se aos feitos da burguesia brasileira no processo de consolidação de seus interesses, mas, em nossa análise, a matriz deste apagamento aparece na própria compreensão de trabalho que a autora revela: nela, os homens estão dissociados de sua potencialidade de gênero.

Pensar o lazer à luz da obra de Marx e Engels pede a análise dos nexos e contradições em que está inscrita esta prática social, seja enquanto categoria da economia política; seja enquanto expressão objetiva de necessidades humanas; seja como ferramenta política de construção de hegemonia; seja como ferramenta revolucionária de auto-organização de classe com vistas à superação do modo capitalista de produção da existência enquanto modelo concentrador, excludente e opressivo da classe trabalhadora. Parte da lógica do modo como os homens organizam a produção e a reprodução de sua existência, o lazer expressa as contradições internas do modo capitalista de produção, tornando-se um desafio para os estudiosos do lazer expor as possibilidades objetivas ali engendradas que apontam perspectivas no processo de construção da superação destas mesmas condições objetivas alienadas e alienantes que ali se configuram.

Movimento, Porto Alegre, v.13, n. 02, p.197-218, maio/agosto de 2007. 


\begin{abstract}
Leisure studies and the appropriation of Marx's and Engels' work: Maria Isabel Leme Faleiros

Abstract: State-of-the-art study of leisure studies in Brazil, focused on the works that appropriate Marx's work, produced and disseminated in periodicals and national publishers (in the eighties). Dealing with leisure as a social practice strictly limited to the sphere of production and reproduction of existence; the forecast of emancipatory possibilities/perspectives in this social practice; and the total denial of work/leisure as spheres of human achievement, these texts introduce to the readers the instigating question of work and leisure perspectives - of the need and freedom - in the capitalist society as well as in the communist project. Keywords: Leisure activities. Brasil. Literature. Comunism. Karl Marx. Friedrich Engels.
\end{abstract}

\begin{tabular}{l}
\hline El Estudio del Ocio y la Apropiación de la Obra \\
de Marx y Engels: Maria Isabel Leme Faleiros \\
Resumen: El estudio del estado del arte en los \\
estudios del ocio en Brasil, concentrados en los \\
trabajos que apropian la obra de Marx, producidos \\
y diseminados en periódicos y editoras nacionales. \\
Transitando entre la colocación del ocio como \\
práctica social estrictamente limitada a la esfera \\
de producción y de la reproducción de la existencia; \\
la vislumbre de posibilidades/perspectivas \\
emancipatorias en esta práctica social; y la total \\
negación del trabajo/ocio como esfera de \\
realización humana, estos textos presentan a los \\
lectores la incitante cuestión de las perspectivas \\
del trabajo y del ocio en la sociedad capitalista y \\
en el proyecto comunista. \\
Palabras clave: Actividades recreativas. Brasil. \\
Literatura. Comunismo. Karl Marx. Friedrich Engels.
\end{tabular}

\title{
REFERÊNCIAS
}

BRAGA, L. S. Uma civilização sem alma? Educação e revolução passiva. 2005. 191f. Dissertação (Mestrado) Faculdade de Educação - Universidade Estadual de Campinas, Campinas.

CUNHA, N. A felicidade imaginada: a negação do trabalho e do lazer. São Paulo: Brasiliense, 1987.

Movimento, Porto Alegre, v.13, n. 02, p.197-218, maio/agosto de 2007. 
FALEIROS, M. I. L. Repensando o lazer. Perspectiva, São Paulo, n.3, p.51-65, 1980.

FAUSTO, B. História concisa do Brasil. São Paulo: EDUSP, 2006.

GANDRA, E. Á.; SILVA, A. J.; NASCIMENTO, M. I. M. A orientação político-educacional no populismo e a evolução da estratégia liberal para conter a mobilização operária. Revista HISTEDBR, Campinas, n.19, p.117-133, set. 2005. Disponível em: <http://www.histedbr.fae.unicamp.br/revis.html>. Acesso em: 10 fev. 2007.

GOMES, C. L. Significados da recreação e lazer no Brasil: reflexões a partir da análise de experiências institucionais (1926-1964). 2003. 322f. Tese (Doutorado) - Faculdade de Educação, Universidade Federal de Minas Gerais, Belo Horizonte.

LOPES, M. I. S. É pirueta pra cavar o ganha-pão. Reflexão, Campinas, v.11, n.35, p. 33-37, maio/ago. 1986.

MARCASSA, L. A invenção do lazer: educação, cultura e tempo livre na cidade de São Paulo. (1888-1935). 2002. 204f. Dissertação (Mestrado) - Faculdade de Educação, Universidade Federal de Goiás, Goiânia.

MARCELLINO, N. C. Lazer e humanização. Campinas: Papirus, 1983.

Lazer e educação. Campinas: Papirus, 1987.

MARX, C. Grundisse: lineamentos fundamentales para la crítica de la economía política (1857-1858). México: Fondo de Cultura Económica, 1985.

Glosas críticas al artículo "el rey de Prusia y la reforma social. Por un prusiano". In: MARX, C.; ENGELS, F. Obras fundamentales: Carlos Marx: escritos de juventud. México: Fondo de Cultura Económica, 1982. v.1, p. 505-521.

Los debates de la VI Dieta Renana: debates sobre la ley castigando los robos de leña. In: MARX, C.; ENGELS, F. Obras fundamentales: Carlos Marx: escritos de juventud. México: Fondo de Cultura Económica, 1982. v.1, p. 248-283.

Los debates de la VI Dieta Renana: los debates sobre la libertad de prensa y la publicación de los debates de la dieta. In: MARX, C.; ENGELS, F. Obras fundamentales: Carlos Marx: escritos de juventud. México: Fondo de Cultura Económica, 1982. v.1, p.173-219.

. Sobre la cuestión judía. In: MARX, C.; ENGELS, F. Obras fundamentales: Carlos Marx: escritos de juventud. México: Fondo de Cultura Económica, 1982, v.1, p. $463-490$.

MARX, K. Introdução: temas de ciências humanas. In: do direito de Hegel. São Paulo: Grijalbo, 1977. v. $\overline{2, \text { p.1-14. }}$.

Crítica da filosofia

Movimento, Porto Alegre, v.13, n. 02, p.197-218, maio/agosto de 2007. 
Trabalho alienado e superação positiva da auto-alienação humana. In FERNANDES, F. Marx e Engels: história. São Paulo: Ática, 1989.

Crítica ao programa de Gotha. In: MARX, K.; ENGELS, F. Obras escolhidas. São Paulo: Alfa Omega, 1980.

Manuscritos econômico-filosóficos e outros textos escolhidos: seleção de textos de José Arthur Giannotti. 2. ed. São Paulo: Abril Cultural, 1978. (Os Pensadores).

1989.

O Capital: crítica da economia política. Rio de Janeiro: Bertrand Brasil, 2003

Trabalho estranhado (extrato). Idéias, Campinas, v.9, n.2, p. 455-472,

Manuscritos econômico filosóficos. São Paulo: Boitempo, 2004.

O 18 de Brumário de Luís Bonaparte. In:

Manuscritos econômico-filosóficos e outros textos escolhidos. São Paulo: Abril Cultural, 1978. (Os Pensadores).

MARX, K.; ENGELS, F. A ideologia alemã. São Paulo: Martins Fontes, 1980.

Cartas filosóficas e o manifesto comunista de 1848. São Paulo: Moraes, 1987. p. 102-116.

Obras escolhidas. São Paulo: Alfa Ômega, 1980.

MEDEIROS, E. B. Reminiscências de uma educadora: mais de meio século de trabalho em Recreação e Lazer. In: SEMINÁRIO “O LAZER EM DEBATE”, 4., 2003, Belo Horizonte. Coletânea... Belo Horizonte: UFMG/DEF/CELAR, 2003.

OLIVEIRA, P. S. Tempo livre, trabalho e lutas sociais. Reflexão, Campinas, n.35, p. 7-14, 1986.

PICHELI, V. O IDORT enquanto proposta educacional no contexto de formação da hegemonia burguesa no Brasil 1930-1945. 1997. Dissertação (Mestrado) - Faculdade de Educação, Universidade Estadual de Campinas, Campinas.

REALE, M. O direito de não trabalhar. In: Tendências do direito do trabalho contemporâneo. São Paulo: LTR, 1980. p. 115-120.

SANT'ANNA, D. B. O prazer justificado: história e lazer (1969-1979). São Paulo: Marco Zero/MCT/CNPq, 1994.

SODRÉ, F. As necessidades dos operários brasileiros. Revista de Estudos Brasileiros, São Paulo, v.1, n.1, p.66-82, jul./ago. 1938.

SUSSEKIND, A.; MARINHO, I. P.; GÓES, O. Manual de recreação: orientação

Movimento, Porto Alegre, v.13, n. 02, p.197-218, maio/agosto de 2007. 
dos lazeres do trabalhador. Rio de Janeiro: Ministério do Trabalho, Indústria e Comércio, 1952.

SUSSEKIND, A. A chave do sucesso: Arnaldo Sussekind: um cidadão ilustre. Revista Prática Jurídica, Brasília, v.3, n.30, p. 6-9, set. 2004.

Duração do trabalho e repousos remunerados. Rio de Janeiro: Freitas Bastos, 1950.

Recreação operária. Rio de Janeiro: Ministério do Trabalho, Indústria e Comércio, 1948.

Trabalho e recreação: fundamentos, organização e realizações da S.R.O. Rio de Janeiro: Ministério do Trabalho, Indústria e Comércio, 1946.

Movimento, Porto Alegre, v.13, n. 02, p.197-218, maio/agosto de 2007. 